\title{
Prevalence and spectrum of NKX2.5 mutations in patients with congenital atrial septal defect and atrioventricular block
}

\author{
YING-JIA XU $^{1}$, XING-BIAO QIU ${ }^{1}$, FANG YUAN $^{1}$, HONG-YU SHI $^{1}$, LEI XU $^{1}$, XU-MIN HOU $^{1}$, \\ XIN-KAI QU ${ }^{1}, X_{\text {LIU }}^{1}$, RI-TAI HUANG ${ }^{2}$, SONG XUE ${ }^{2}$, YI-QING YANG ${ }^{1,3}$ and RUO-GU LI ${ }^{1}$ \\ ${ }^{1}$ Department of Cardiology, Shanghai Chest Hospital, Shanghai Jiao Tong University, Shanghai 200030; \\ ${ }^{2}$ Department of Cardiovascular Surgery, Renji Hospital, School of Medicine, Shanghai Jiao Tong University, \\ Shanghai 200127; ${ }^{3}$ Department of Cardiology, Cardiovascular Research Laboratory and Central Laboratory, \\ Shanghai Chest Hospital, Shanghai Jiao Tong University, Shanghai 200030, P.R. China
}

Received January 6, 2016; Accepted December 21, 2016

DOI: $10.3892 / \mathrm{mmr} .2017 .6249$

\begin{abstract}
Congenital atrial septal defect (ASD) and progressive atriventricular block (AVB) are the two most common phenotypes linked to NK2 homeobox 5 (NKX2.5) mutations in animals and humans. However, the prevalence and spectrum of NKX2.5 mutation in patients with ASD and AVB remain to be elucidated. In the present study, the coding exons and flanking introns of the $N K X 2.5$ gene, which encodes a homeobox-containing transcription factor essential for development of the heart, were sequenced in a cohort of 62 unrelated patients with ASD and AVB, and subsequently in a mutation carrier's available family members. As controls, 300 unrelated, ethnically-matched healthy individuals were recruited, who were also genotyped for $N K X 2.5$. The functional consequence of the mutant NKX2.5 was evaluated in contrast to its wild-type counterpart using a dual-luciferase reporter assay system. As a result, a novel heterozygous NKX2.5 mutation, p.Q181X, was identified in an index patient with ASD and AVB, with a prevalence of $\sim 1.61 \%$. Genetic analysis of the proband's pedigree revealed that the mutation co-segregated with ASD and AVB with complete penetrance. The nonsense mutation, which eliminated partial homeobox and the carboxyl terminus, was absent in the 600 control chromosomes. Functional evaluation showed that the NKX2.5 mutant had no transcriptional activity. Furthermore, the
\end{abstract}

Correspondence to: Dr Ruo-Gu Li, Department of Cardiology, Shanghai Chest Hospital, Shanghai Jiao Tong University, 241 West Huaihai Road, Shanghai 200030, P.R. China

E-mail: liruogu98@163.com

Dr Yi-Qing Yang, Department of Cardiology, Cardiovascular Research Laboratory and Central Laboratory, Shanghai Chest Hospital, Shanghai Jiao Tong University, 241 West Huaihai Road, Shanghai 200030, P.R. China

E-mail: dryyq@tongji.edu.cn

Key words: atrial septal defect, atrioventricular block, genetics, transcription factor, NK2 homeobox 5, reporter gene analysis mutation disrupted the synergistic activation between NKX2.5 and GATA binding protein 4 , another cardiac core transcription factor associated with ASD. The results of the present study expand the spectrum of NKX2.5 mutations linked to ASD and AVB, and indicated that NKX2.5 loss-of-function mutations are an uncommon cause of ASD and AVB in humans.

\section{Introduction}

The heart is the first organ to form during embryogenesis and a sufficient supply of oxygen and nutrients through the circulatory system is an essential prerequisite for embryonic growth and survival (1). The formation of a fully functional four-chambered heart from the early embryo involves a precisely coordinated process of cellular differentiation and integrated multi-cellular morphogenesis, and even slight perturbations of this biological process may lead to cardiac developmental abnormalities, which is highlighted by the fact that congenital heart disease (CHD) is the most common form of birth defect in humans, with an estimated prevalence of $1 \%$ in live births, and up to $10 \%$ of stillbirths (1-4). Congenital heart defects can be classified into two major categories of morphological malformations and functional anomalies, including cardiac arrhythmias and cardiomyopathies. Cardiac structural deformities are a leading contributor to infant morbidity and mortality rates, whereas defects in the development of cardiac conduction system confer a significantly increased risk of mortality throughout life (5). Although the genetic basis underpinning a number of these defects remains to be elucidated, the core cardiac transcription factors, which are expressed predominantly in the heart and mediate the expression of genes encoding cardiac structural proteins or regulatory proteins, are increasingly recognized as being important in the normal development of the heart (6). Mutations in certain genes encoding core cardiac transcription factors, including homeodomain-containing NK2 homeobox 5 (NKX2.5) and NKX2.6 (7-16), GATA-binding protein (GATA) 4, GATA5 and GATA6 (17-24), T-box protein (TBX) 5 and TBX20 (25-29), and a paired-like homeobox transcription factor, PITX2 (30-33), have emerged as major contributors to several types of congenital heart defects $(2,5,6,34)$. 
During the last decade, increasing evidence has demonstrated the essential role of the NKX2.5 transcription factor in embryonic cardiogenesis and postnatal cardiac adaptation, particularly in the development of the cardiac conduction system (1). In mice, NKX2.5 is expressed at high levels in the early heart progenitor cells of primary and secondary heart fields during embryonic morphogenesis, and continues to be expressed at a high level in the heart through adulthood (1). Of note, the expression of NKX2.5 is transiently elevated in specialized myocardial conduction cells during formation of the conduction system, indicating the importance of NKX2.5 in the development of the conduction system (1). In murine embryos completely null for $N k x 2.5$, embryonic death occurred at $\sim$ E9-10 due to arrested looping morphogenesis of the heart tube and growth retardation $(35,36)$. In addition, in $N k x 2.5$-knockoutmice, the number of cells in the cardiac conduction system were found to be directly associated with Nkx2.5 gene dosage, with homozygous mutant embryos lacking the primordium of the atrioventricular node (37). By contrast, mice homozygous for a ventricle-restricted knockout of $N k \times 2.5$ showed no cardiovascular structural defects, but exhibited marked overgrowth of trabecular muscle and progressive complete heart block owing to hypoplastic atrioventricular node at birth (38). In humans, mutations in $N K X 2.5$ have been associated with a wide spectrum of cardiovascular diseases, including congenital heart defects, such as atrial septal defect (ASD), ventricular septal defect, tetralogy of Fallot, bicuspid aortic valve, mitral valve deformations, subvalvular aortic stenosis, abnormal systemic venous return, hypoplasia of left heart and visceral situs inversus (2,5-9,39), dilated cardiomyopathy (10), arrhythmias, such as atrioventricular block (AVB), atrial fibrillation and ventricular tachycardia (10-12,34,40-42), and sudden cardiac death $(12,43,44)$, of which ASD and AVB are the two most frequent phenotypes in patients carrying NKX2.5 mutations. Of note, in a murine knock-in model generated by knocking in a comparable $N K X 2.5$ missense mutation (p.R52G) previously identified in patients, pleiotropic cardiac anomalies, including ASD, ventricular septal defect, atrioventricular septal defect, Ebstein malformation of the tricuspid valve and ventricular noncompaction were observed, in addition to progressive AVB, and this was similar or more marked, compared with the cardiac anomalies found in humans harboring a heterozygous mutation of p.R52 G in NKX2.5 $(45,46)$. These observational results suggest that $N K X 2.5$ mutations are responsible for ASD and AVB, and evaluation of the prevalence and spectrum of NKX2.5 mutations in patients with congenital ASD and AVB is warranted. This study was sought to evaluate the prevalence and spectrum of NKX2.5 mutations in patients with congenital ASD and AVB.

\section{Materials and methods}

Study population. In the present study, 62 unrelated patients with congenital ASD and AVB were recruited from the Chinese Han population, who were admitted to Shanghai Chest Hospital from January 2011 to December 2013. The available family members of the index patient carrying an identified NKX2.5 mutation were also included. In addition, 300 unrelated healthy individuals, who were matched to the patients with ASD and AVB in ethnicity, gender and age, were recruited as controls. All study subjects underwent detailed clinical investigation, including familial, personal and medical histories, physical examination, routine laboratory tests in hospitals, transthoracic echocardiography, and standard 12-lead electrocardiogram. The clinical types of CHDs were determined using two-dimensional continuous wave Doppler and color Doppler techniques on transthoracic echocardiography. When there was a strong indication, transesophageal echocardiography, cardiac catheterization and angiography were performed to further clarify the cardiovascular anatomic malformations. The definition and classification of AVB, which are widely used clinically and are based on the extent (first, second or third degree) of a block and the site within the conduction system of a block, were described previously (47). In brief, first-degree AVB is referred to as prolongation of the PR interval, which is the time interval between onset of P-wave and onset of QRS complex, on the surface electrocardiogram. In second-degree AVB, certain atrial impulses are conducted to the ventricles; electrocardiographic manifestation is the association of certain QRS complexes with P waves. Second-degree AVB is further classified as type 1 or type 2 . In type 1 block, progressive prolongation of the PR interval is observed prior to the occurrence of AVB (Wenckebach periodicity). In type 2, the block occurs abruptly without PR interval prolongation. In third-degree or complete AVB, no atrial impulses conduct to the ventricles; on the electrocardiogram, QRS complexes are independent of $\mathrm{P}$ waves. In certain cases, AVB is described as progressive if the electrocardiographic characterization of atrioventricular conduction worsens over time, for example when the block progresses from second to third degree (47). Patients with ASD who suffered from AVB following cardiac surgery or intervention for CHD, or had chromosomal abnormalities or syndromic cardiovascular anomalies, including Holt-Oram syndrome, Di George syndrome, Alagille syndrome and Axenfeld-Rieger syndrome, were excluded from the present study. The present study was performed in accordance with the principles outlined in the Declaration of Helsinki. The study protocol was reviewed and approved by the Ethics Committee of Shanghai Chest Hospital, Shanghai Jiao Tong University (Shanghai, China). Written informed consent was obtained from all adult participants and from parents of minors prior to the investigation.

Mutational analysis of NKX2.5. Peripheral venous blood samples $(3 \mathrm{ml})$ were collected from the patients and control individuals. Genomic DNA was extracted from blood leukocytes (for most steps in the DNA purification procedure, centrifugation at a speed of 2,000 $\mathrm{x} g$ for $10 \mathrm{~min}$ at $-4^{\circ} \mathrm{C}$ ) using a Wizard Genomic DNA Purification kit (Promega, Madison, WI, USA), according to the manufacturer's protocol. With the assistance of online Primer 3 software (http://bioinfo.ut.ee/primer3-0.4.0/), the primers used to amplify the coding exons and flanking introns of $N K X 2.5$ by polymerase chain reaction (PCR) were designed as shown in Table I. The referential genomic DNA sequence of $N K X 2.5$ was derived from GenBank (https://www.ncbi.nlm.nih. gov/nuccore/NG_013340.1; accession no. NG_01,3340.1). PCR was performed with HotStar Taq DNA polymerase 
Table I. Primers for amplification of coding exons and flanking introns of NK2 homeobox 5.

\begin{tabular}{lllc} 
Exon & Forward primer (5'-3') & Reverse primer (5'-3') & $\begin{array}{c}\text { Amplicon } \\
\text { size (bp) }\end{array}$ \\
\hline 1 & CTTGTGCTCAGCGCTACCTG & TCTTGGGGACGAAAGCGACC & 543 \\
$2-\mathrm{a}$ & CCGTAGGTCAAGCCGCTCTT & ACGAAGTTGTTGTGGCGGC & 599 \\
$2-\mathrm{b}$ & GCGTGCTGAAACTCACGTCC & GGTCATGTTGGGAGCCCCTT & 545 \\
\hline
\end{tabular}

(Qiagen $\mathrm{GmbH}$ ) on a Veriti thermal cycle (Applied Biosystems; Thermo Fisher Scientific, Inc., Waltham, MA, USA). The total volume of a PCR mixture was $25 \mu 1$, encompassing $2.5 \mu 110 \mathrm{X}$ buffer, $11.25 \mu \mathrm{l}$ deionized water, $5 \mu 15 \mathrm{X} \mathrm{Q}$ solution, $1 \mu \mathrm{l}$ of each primer at $20 \mu \mathrm{M}, 2 \mu \mathrm{l}$ of dNTPs $(2.5 \mathrm{mM}$ each), $0.25 \mu \mathrm{l}$ of HotStar Taq DNA Polymerase at $5 \mathrm{U} / \mu \mathrm{l}$ (Qiagen $\mathrm{GmbH}$ ) and $2 \mu \mathrm{l}$ of genomic DNA at $200 \mathrm{ng} / \mu \mathrm{l}$. The PCR cycling parameters were as follows: Pre-denaturation of template and activation of the DNA polymerase at $95^{\circ} \mathrm{C}$ for $15 \mathrm{~min}$, followed by 35 cycles of denaturation at $94^{\circ} \mathrm{C}$ for $30 \mathrm{sec}$, annealing at $62^{\circ} \mathrm{C}$ for $30 \mathrm{sec}$ and extension at $72^{\circ} \mathrm{C}$ for $1 \mathrm{~min}$, with a final extension at $72^{\circ} \mathrm{C}$ for $6 \mathrm{~min}$. The PCR-generated amplicons were purified and sequenced with $N K X 2.5$-specific primers using a BigDye ${ }^{\circledR}$ Terminator v3.1 Cycle Sequencing kit (Applied Biosystems; Thermo Fisher Scientific, Inc.) under an ABI PRISM 3130 XL DNA analyzer (Applied Biosystems; Thermo Fisher Scientific, Inc.). For an identified sequence variation in $N K X 2.5$, its numbering began from nucleotide $\mathrm{A}$ of the initial translation codon ATG (accession no. NM_004387.3). To verify the novelty of an identified $N K X 2.5$ sequence variation, the single nucleotide polymorphism (SNP; http://www.ncbi.nlm. nih.gov/SNP) database, the 1000 Genomes Project $(1000 \mathrm{G}$; http://www.1000genomes.org) database, the exome variant server (EVS; http://evs.gs.washington.edu/EVS) database and the human genome mutation (HGM; http://www.hgmd.org/) database were queried.

Alignment of multiple NKX2.5 proteins across species. The NKX2.5 protein sequences of humans were aligned with those of chimpanzee, monkey, dog, cattle, mouse, rat, fowl, zebrafish and frog using the online MUSCLE program (version, 3.6; http://www.ncbi.nlm.nih.gov/homologene?cmd=Retrieve\&do pt=MultipleAlignment\&list_uids=3230).

Expression plasmids and site-directed mutagenesis. The recombinant expression plasmidsNKX2.5-pEFSA and GATA4-pSSRa, and the atrial natriuretic factor (ANF)-luciferase; ANF-luc) reporter plasmid, which contained 2,600 base pairs upstream of the transcriptional start site of the $A N F$ gene and expresses Firefly luciferase, were provided by Dr Ichiro Shiojima at the Department of Cardiovascular Science and Medicine, Chiba University Graduate School of Medicine (Chiba, Japan). The identified mutation was introduced into the wild-type NKX2.5-pEFSA construct by site-directed mutagenesis using a complementary pair of primers (forward, 5'-AAACTCACGTCCACGTAGGTCAAG ATCTGGT-3'; reverse, 5'-ACCAGATCTTGACCTACGTGG ACGTGAGTTT-3') and the Quick Change II XL Site-Directed
Mutagenesis kit (Stratagene; Agilent Technologies, Santa Clara, CA, USA), and confirmed by direct sequencing.

Cell culture, transfection and reporter gene assays. COS-7 cells, which were obtained from the cell bank at the Cardiovascular Research Laboratory of Shanghai Chest Hospital (Shanghai, China). The cells were cultured in Dulbecco's modified Eagle's medium (Gibco; Thermo Fisher Scientific, Inc.) supplemented with $10 \%$ fetal bovine serum (Gibco; Thermo Fisher Scientific, Inc.), $100 \mu \mathrm{g} / \mathrm{ml}$ penicillin and $100 \mu \mathrm{g} / \mathrm{ml}$ streptomycin under an atmosphere of $5 \%$ $\mathrm{CO}_{2}$ at $37^{\circ} \mathrm{C}$. Transient transfections of cells at $\sim 90 \%$ confluence were performed with Lipofectamine ${ }^{\circledR} 2000$ reagent (Invitrogen; Thermo Fisher Scientific, Inc.) $24 \mathrm{~h}$ post-seeded at a cell density of about $1 \times 10^{5}$ per well in 12 -well plates. The internal control pGL4.75 plasmid (Promega Corp.), which expresses Renilla luciferase, was used in transfection assays to normalize transfection efficiency. The COS-7 cells were transfected with $0.4 \mu \mathrm{g}$ wild-type or Q181X-mutant NKX2.5-pEFSA, in combination with $1.0 \mu \mathrm{g}$ ANF-luc and $0.04 \mu \mathrm{g}$ pGL4.75. For co-transfection experiments, $0.2 \mu \mathrm{g}$ wild-type NKX2.5-pEFSA, $0.2 \mu \mathrm{g}$ of Q181X-mutant NKX2.5-pEFSA, $1.0 \mu \mathrm{g}$ of ANF-luc and $0.04 \mu \mathrm{g}$ of pGL4.75 were used. For analysis of the synergistic transcriptional activation between NKX2.5 and GATA4, the COS-7 cells were transfected with the same quantity $(0.2 \mu \mathrm{g})$ of each plasmid DNA (wild-type NKX2.5-pEFSA, GATA4-pSSRa, or Q181X-mutant NKX2.5-pEFSA) was used alone or in combination, in the presence of $1.0 \mu \mathrm{g}$ ANF-luc and $0.04 \mu \mathrm{g}$ pGL4.75. At $6 \mathrm{~h}$ post-transfection, the media was replaced with growth media and cells were maintained for $48 \mathrm{~h}$. The transfected cells were washed twice with PBS and lysed using PLB buffer (Promega Corp.) for incubation at room temperature for $15 \mathrm{~min}$. The Firefly and Renilla luciferase activities were measured using a Dual-Luciferase Reporter Assay system (Promega Corp.) according to the manufacturer's protocol. The activity of the $A N F$ promoter was determined as the fold activation of Firefly luciferase relative to Renilla luciferase. Three independent experiments were performed in triplicate for each cell transfection, and each value presented as the average of triplicate samples.

Statistical analysis. Statistical analyses were performed using SPSS version 18.0 (SPSS, Inc., Chicago, IL, USA). Continuous variables with normal distribution are expressed as mean and standard deviations. Categorical variables are expressed as numbers and percentages. Differences between two groups were compared using Student's unpaired $t$-test for continuous variables, and with the $\chi^{2}$ test or Fisher's exact test 
Table II. Baseline clinical characteristics of the study population.

\begin{tabular}{|c|c|c|c|}
\hline Variable & $\begin{array}{c}\text { Patients }(\mathrm{n}=62) \\
\mathrm{n}(\%)\end{array}$ & $\begin{array}{c}\text { Controls }(\mathrm{n}=300) \\
\mathrm{n}(\%)\end{array}$ & P-value \\
\hline Age (years) & $31 \pm 15$ & $32 \pm 7$ & 0.4200 \\
\hline Male & $39(63)$ & $190(63)$ & 0.9490 \\
\hline Family history of ASD and AVB & $6(10)$ & $0(0)$ & $<0.0001$ \\
\hline History of syncope & $15(24)$ & $0(0)$ & $<0.0001$ \\
\hline Implanted cardiac pacemaker & $18(29)$ & $0(0)$ & $<0.0001$ \\
\hline Surgical or catheter-based ASD closure & $41(66)$ & $0(0)$ & $<0.0001$ \\
\hline \multicolumn{4}{|l|}{ Distribution of types of ASD } \\
\hline Ostium secundum ASD & $51(82)$ & $0(0)$ & $<0.0001$ \\
\hline Ostium primum ASD & $9(15)$ & $0(0)$ & $<0.0001$ \\
\hline Sinus venosus ASD & $2(3)$ & $0(0)$ & 0.0289 \\
\hline \multicolumn{4}{|l|}{ Distribution of types of AVB } \\
\hline First-degree AVB & $34(55)$ & $0(0)$ & $<0.0001$ \\
\hline Second-degree AVB & $12(19)$ & $0(0)$ & $<0.0001$ \\
\hline Third-degree AVB & $16(26)$ & $0(0)$ & $<0.0001$ \\
\hline
\end{tabular}

ASD, atrial septal defect; AVB, atrioventricular block.

for categorical variables. $\mathrm{P}<0.05$ (two-tailed) was considered to indicate a statistically significant difference.

\section{Results}

Clinical characteristics of the study population. In the present study, 62 unrelated patients with ASD and AVB were clinically evaluated for comparison with 300 unrelated healthy individuals. All patients had congenital ASD, confirmed by echocardiogram, and AVB, confirmed by electrocardiogram. There were six patients who also had a positive family history of ASD and AVB. Based on their medical histories, echocardiographic records and electrocardiographic results, the control individuals had neither CHD nor AVB. None of the control individuals had a family history of ASD or AVB. No statistical differences were found in ethnicity, gender or age between the patient and control groups. The baseline clinical characteristics of the study population are shown in Table II.

Identification of a novel NKX2.5 mutation. Sequence analysis of the $N K X 2.5$ gene in 62 unrelated patients with ASD and AVB revealed a heterozygous substitution of thymine for cytosine in the first nucleotide of codon 181 (c.541C $>\mathrm{T}$ ) in the index patient; this mutation was predicted to introduce a stop codon at amino acid 181, resulting in the production of a truncated protein with only the $\mathrm{NH}_{2}$-terminal 180 amino acids remaining (p.Q181X). The DNA sequencing electropherograms showing the NKX2.5 mutation of c.541C $>\mathrm{T}$ and its control sequence are shown in Fig. 1A. A schematic diagram of the NKX2.5 protein showing the functionally important structural domains and the location of the mutation identified in the present study is shown in Fig. 1B. The nonsense mutation was not detected in the 300 control individuals or in the SNP, $1000 \mathrm{G}$, EVS and HGM databases. Genotyping $N K X 2.5$ in the proband's available family members showed that the heterozygous mutation was present in all three affected family members and absent in all four unaffected family members. Genetic analysis of the proband's pedigree unveiled that the mutation co-segregated with ostium secundum ASD and progressive AVB, which were transmitted in an autosomal dominant pattern with complete penetrance. In addition, the proband's father had ventricular septal defect and atrial fibrillation, and succumbed to mortality at the age of 60 years. The proband's younger sister also had an incomplete right bundle branch block. All the living affected family members underwent catheter-based closure of ASD. The pedigree structure of the family is illustrated in Fig. 1C. The clinical features of the affected family members are shown in Table III.

Alignment of the NKX2.5 proteins from various species. Alignment of the human NKX2.5 protein with those of chimpanzee, monkey, dog, cattle, mouse, rat, fowl, zebrafish and frog showed that the altered amino acid, p.Q181, was completely conserved evolutionarily (Fig. 2).

Functional failure of NKX2.5 protein resulted from mutation. As shown in Fig. 3, the same quantity $(0.4 \mu \mathrm{g})$ of wild-type and Q181X-mutant NKX2.5 transcriptionally activated the ANF promoter by $\sim 12$-fold and $\sim 1$-fold, respectively (wild-type, vs. mutant; $t=15.0303, \mathrm{P}=0.0001$ ); whereas $0.2 \mu \mathrm{g}$ of wild-type NKX2.5 with $0.2 \mu \mathrm{g}$ Q181X-mutant NKX2.5 activated the $A N F$ promoter by $\sim 6$-fold $(0.4 \mu \mathrm{g}$ of wild-type, vs. $0.2 \mu \mathrm{g}$ mutant $+0.2 \mu \mathrm{g}$ wild-type; $t=6.5294, \mathrm{P}=0.0028)$.

Disrupted synergistic activation between NKX2.5 and GATA4 by the mutation. As shown in Fig. 4, the same quantity $(0.2 \mu \mathrm{g})$ of wild-type NKX2.5, GATA4 and Q181X-mutant NKX2.5 activated the $A N F$ promoter by $\sim 7$-fold, $\sim 2$-fold and $\sim 1$-fold, respectively. In the presence 
Table III. Clinical features and mutational status of NKX2.5 in affected family members.

\begin{tabular}{lccccc}
\hline Individual & Gender & $\begin{array}{c}\text { Age } \\
\text { (years) }\end{array}$ & $\begin{array}{c}\text { Cardiac structural } \\
\text { defects }\end{array}$ & $\begin{array}{c}\text { Cardiac } \\
\text { arrhythmias }\end{array}$ & $\begin{array}{c}\text { Q181X } \\
\text { mutation }\end{array}$ \\
\hline I-1 & M & $60^{\mathrm{a}}$ & ASD, VSD & III $^{0}$ AVB, AF & NA \\
II-1 & M & 47 & ASD & II $^{0}$ AVB & $+/-$ \\
II-6 & F & 41 & ASD & II $^{0}$ AVB, IRBBB & $+/-$ \\
III-3 & M & 16 & ASD & I $^{0}$ AVB & $+/-$ \\
\hline
\end{tabular}

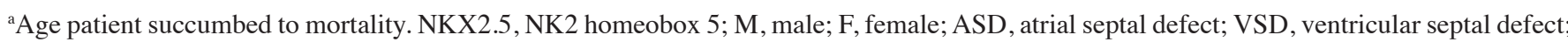
$\mathrm{AVB}$, atrioventricular block; $\mathrm{I}^{0}$, first-degree; $\mathrm{II}^{0}$, second-degree; $\mathrm{III}^{0}$, third-degree; AF, atrial fibrillation; IRBBB, incomplete right bundle branch block; +/-, heterozygous for Q181X mutation of NKX2.5; NA, not available.

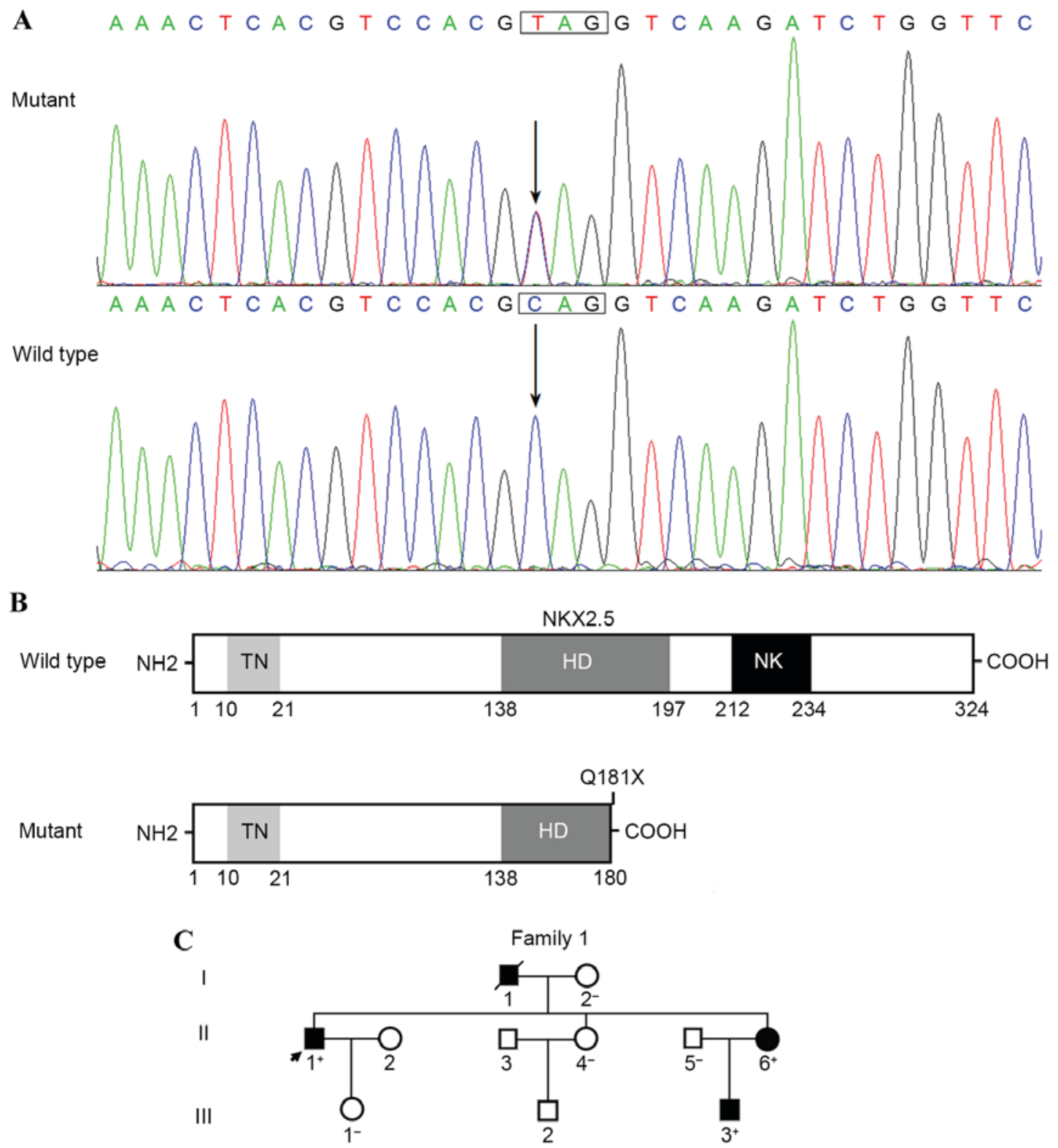

Figure 1. A novel NKX2.5 mutation associated with familial ASD and AVB. (A) Sequence electropherograms show the heterozygous NKX2.5 mutation and its wild-type control. The arrow indicates the heterozygous nucleotides of C/T in the index patient with congenial ASD and AVB (mutant) or the homozygous nucleotides of $\mathrm{C} / \mathrm{C}$ in the corresponding control subject (wild-type). The rectangle marks the nucleotides that comprise a codon of $N K X 2.5$. (B) Schematic diagram illustrating the structural domains of NKX2.5. The mutation identified in patients with congenial ASD and AVB is shown above the truncated protein (mutant). (C) Pedigree structure of a family with congenial ASD and AVB, designated as family 1 . Family members are identified as generations and numbers. Squares, male family members; circles, female family members; closed symbols, affected; open symbols, unaffected; symbol with a slash, deceased member; arrow, proband; +, carriers of the heterozygous mutation; -, non-carriers; NKX2.5, NK2 homeobox 5; NH2, amino-terminus; TN, tinman domain; $\mathrm{HD}$, homeodomain; NK, nucleotide kinase domain; COOH, carboxyl-terminus; ASD, atrial septal defect; AVB, atrioventricular block. 


\begin{tabular}{|c|c|c|c|}
\hline & \multicolumn{3}{|c|}{ Q181X } \\
\hline & 157 & & 205 \\
\hline NP_004378.1 (human) & ---FKQQRYLSAPERDQLASVLKLTST & Q & VKIWFQNRRYKCKRQRQDQTLELV--- \\
\hline XP_518104.2 (chimpanzee) & ---FKQQRYLSAPERDQLASVLKLTST & Q & VKIWFQNRRYKCKRQRQDQTLELV--- \\
\hline XP_001096796.1 (monkey) & ---FKQQRYLSAPERDQLASVLKLTST & Q & VKIWFQNRRYKCKRQRQDQTLELV--- \\
\hline NP_001010959.1 (dog) & ---FKQQRYLSAPERDQLASVLKLTST & Q & VKIWFQNRRYKCKRQRQDQTLELV--- \\
\hline NP_001039908.1 (cattle) & ---FKQQRYLSAPERDQLASVLKLTST & Q & VKIWFQNRRYKCKRQRQDQTLELV--- \\
\hline NP_032726.1 (mouse) & ---FKQQRYLSAPERDQLASVLKLTST & Q & VKIWFQNRRYKCKRQRQDQTLELL--- \\
\hline NP_446103.1 (rat) & ---FKQQRYLSPAERDQLASVLKLTST & Q & VKIWFQNRRYKCKRQRQDQTLELL--- \\
\hline NP_990495.1 (fowl) & ---FKQQKYLSAPERDHLANVLKLTST & Q & VKIWFQNRRYKCKRQRQDQTLEMV--- \\
\hline NP_571496.1 (zebrafish) & ---FKQQKYLSAPERDHLANVLKLTST & Q & VKIWFQNRRYKCKRQRQDQTLEMV--- \\
\hline NP_001116891.1 (frog) & ---FKQQKYLSAPERDHLANVLKLTST & Q & VKIWFQNRRYKCKRQRQDQTLEMV--- \\
\hline
\end{tabular}

Figure 2. Multiple alignments of the NKX2.5 proteins across species. Alignment of the human NKX2.5 protein with those of chimpanzee, monkey, dog, cattle, mouse, rat, fowl, zebrafish and frog demonstrated that the altered glutamine at amino acid of human NKX2.5,181 (indicated by arrow) was completely conserved evolutionarily. NKX2.5, NK2 homeobox 5.

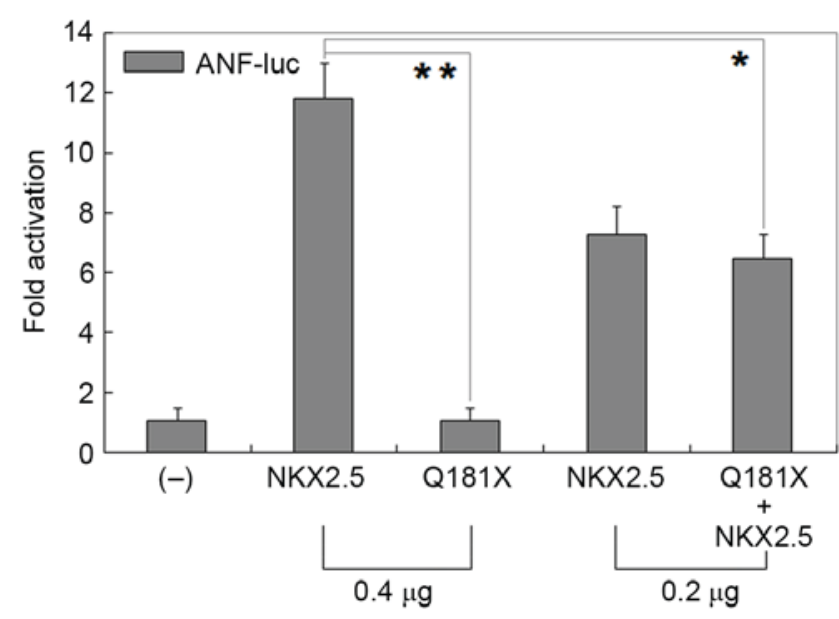

Figure 3. Functional failure of NKX2.5 resulted from mutation. Activation of the ANF promoter driven luciferase in COS-7 cells by wild-type NKX2.5 or Q181X-mutant NKX2.5 (Q181X), alone or together, showed significantly decreased activation by the mutant protein. Experiments were performed in triplicate and data are expressed as the mean \pm standard deviation. ${ }^{* *} \mathrm{P}<0.01$ and ${ }^{*} \mathrm{P}<0.005$, compared with the same quantity of wild-type NKX2.5. ANF, atrial natriuretic factor; NKX2.5, NK2 homeobox 5.

of $0.2 \mu \mathrm{g}$ wild-type GATA4, the same quantity $(0.2 \mu \mathrm{g})$ of wild-type and Q181X-mutant NKX2.5 activated the $A N F$ promoter by $\sim 25$-fold and $\sim 2$-fold, respectively (wild-type, vs. mutant; $t=14.1488, \mathrm{P}=0.0001)$.

\section{Discussion}

In the present study, a novel heterozygous NKX2.5 mutation of p.Q181X was identified in a family with congenital ASD with AVB. The nonsense mutation was absent in 600 control chromosomes from a control population matched for ethnicity, gender and age. The mutation was predicted to yield a truncated protein lacking multiple functionally important domains. Reporter gene assays demonstrated that

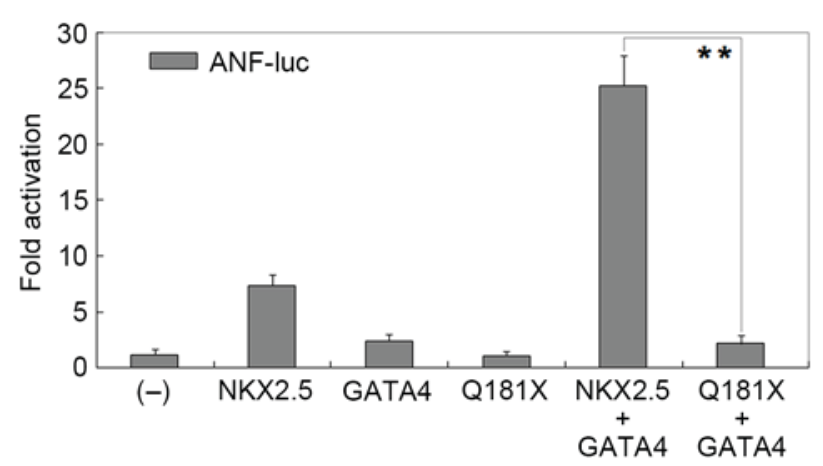

Figure 4. Abrogated synergistic activation between NKX2.5 and GATA4 caused by mutation. Activation of the $A N F$ promoter driven luciferase in COS-7 cells by wild-type NKX2.5 or Q181X-mutant NKX2.5 (Q181X), in the presence of GATA4, revealed disrupted synergistic activation by the mutant protein. Experiments were performed in triplicate and data are expressed as the mean \pm standard deviation. ${ }^{* *} \mathrm{P}<0.001$, compared with its wild-type counterpart. NKX2.5, NK2 homeobox 5; ANF, atrial natriuretic factor; GATA4, GATA binding protein 4.

the Q181X-mutant NKX2.5 protein showed loss of transcriptional activity. Furthermore, the Q181X mutation abrogated the synergistic activation between NKX2.5 and GATA4. Therefore, it is possible that genetically compromised NKX2.5contributed to ASD and AVB in these mutation carriers.

In humans, the $N K X 2.5$ gene is mapped to chromosome $5 q 34$, coding for a protein of 324 amino acids, which is expressed at a high level in the human heart (11). The NKX2.5 protein contains an evolutionarily conserved homeodomain (HD), which is centrally located at amino acid positions 138-197, and functions to specifically recognize and bind to a consensus DNA motif, AAGTG, which is key in the transcriptional regulation of target genes, including $A N F$, brain natriuretic peptide and $\alpha$-actin, either alone or in synergy with other transcription factors, including GATA4, TBX5, TBX20, heart and neural crest derivatives expressed 2 and paired-like 
homeodomain $2(11,19,26,29,31,48,49)$. The NKX2.5 mutation of p.Q181X identified in the present study was located in the $\mathrm{HD}$, and functional analyses revealed that the mutant protein showed loss of the ability to transcriptionally activate $A N F$, alone or together with GATA4. These findings supported $N K X 2.5$ haploinsufficiency as an alternative pathogenic mechanism of ASD and AVB.

ASD is the second most common form of CHD with an estimated incidence of 1/1,500 live births worldwide, accounting for $\sim 10 \%$ of all CHDs $(43,44)$. Although small ASDs may close spontaneously during infancy or childhood, large ASDs or those remaining open into adulthood may cause a significant volume of blood being shunted from the left side of the heart to the right, leading to pneumonia, embolism, pulmonary vascular disease, congestive heart failure, atrial arrhythmias and sudden cardiac death (43). In addition, familial AVB has been observed as congenital or adult-onset type to occur together with ASD (43). Congenital complete AVB is associated with mortality rates ranging between 33 and $80 \%$ if heart rate is $<50$ beats per minute or it co-occurs with structural heart diseases; whereas the adult-onset type of familial AVB is of a progressive nature, and there are several reports of patients with normal electrocardiogram or a harmless first-degree AVB followed by sudden onset of second- and third-degree AVB or sudden cardiac death later in life $(12,43,44)$. Therefore, identification of a novel $N K X 2.5$ mutation underpinning ASD and AVB is of important clinical significance, particularly for genetic counseling in patients carrying the $N K X 2.5$ mutation.

To date, $>60$ mutations in NKX2-5 have been reported to be associated with a wide range of cardiac phenotypes, of which ASD and AVB are the most commonly reported phenotypes, in $\sim 68$ and $66 \%$ of patients, respectively $(43,44)$. In addition, $>97 \%$ of familial cases present with clinically documented ASD and AVB (44). Of note, of all reported non-synonymous mutations, $\sim 1 / 3$ occur within the HD region (44). Functional deciphers of these NKX2.5 mutations have shown reduced transcriptional activity, alone or in synergy with its cooperative partners (44), similar to the present study. Additionally, the results of the present and previous studies $(43,44)$ suggest that there appears to be a genotype-phenotype correlation of NKX2.5 mutations. All mutations causing truncations and all missense mutations in the $\mathrm{HD}$ region result in ASD with AVB.

In conclusion, the present study expands the mutational spectrum of NKX2.5 linked to ASD and AVB, providing additional evidence that the NKX2.5 loss-of-function mutation is an uncommon cause of ASD and AVB.

\section{Acknowledgements}

This study was supported in part by grants from the Key Program for Basic Research of Shanghai, China (grant no. 14JC1405500), the National Natural Science Fund of China (grant nos. 81270161, 81470372 and 81400244), the Natural Science Fund of Shanghai, China (grant nos. 13ZR1438400, 14ZR1438000 and 15ZR1438100) and the Major Development Program for Science and Technology of Shanghai Chest Hospital, Shanghai, China (grant nos. 2014YZDH10102 and 2014YZDH20500).

\section{References}

1. Akazawa $\mathrm{H}$ and Komuro I: Cardiac transcription factor Csx/Nkx2-5: Its role in cardiac development and diseases. Pharmacol Ther 107: 252-268, 2005.

2. Fahed AC, Gelb BD, Seidman JG and Seidman CE: Genetics of congenital heart disease: The glass half empty. Circ Res 112: 707-720, 2013 .

3. Marelli AJ, Ionescu-Ittu R, Mackie AS, Guo L, Dendukuri N and Kaouache M: Lifetime prevalence of congenital heart disease in the general population from 2000 to 2010. Circulation 130: 749-756, 2014.

4. Mozaffarian D, Benjamin EJ, Go AS, Arnett DK, Blaha MJ, Cushman M, de Ferranti S, Després JP, Fullerton HJ, Howard VJ, et al: Heart disease and stroke statistics-2015 update: A report from the American Heart Association. Circulation 131: e29-e322, 2015.

5. McCulley DJ and Black BL: Transcription factor pathways and congenital heart disease. Curr Top Dev Biol 100: 253-277, 2012.

6. Andersen TA, Troelsen Kde L and Larsen LA: Of mice and men: Molecular genetics of congenital heart disease. Cell Mol Life Sci 71: 1327-1352, 2014

7. Qu XK, Qiu XB, Yuan F, Wang J, Zhao CM, Liu XY, Zhang XL, Li RG, Xu YJ, Hou XM, et al: A novel NKX2.5 loss-of-function mutation associated with congenital bicuspid aortic valve. Am J Cardiol 114: 1891-1895, 2014.

8. Izumi K, Noon S, Wilkens A and Krantz ID: NKX2.5 mutation identification on exome sequencing in a patient with heterotaxy. Eur J Med Genet 57: 558-561, 2014.

9. Zheng J, Li F, Liu J, Xu Z, Zhang H, Fu Q, Wang J and Sun K: Investigation of somatic NKX2-5 mutations in Chinese children with congenital heart disease. Int J Med Sci 12: 538-543, 2015.

10. Yuan F, Qiu XB, Li RG, Qu XK, Wang J, Xu YJ, Liu X, Fang WY, Yang YQ and Liao DN: A novel NKX2-5 loss-of-function mutation predisposes to familial dilated cardiomyopathy and arrhythmias. Int J Mol Med 35: 478-486, 2015.

11. Yu H, Xu JH, Song HM, Zhao L, Xu WJ, Wang J, Li RG, Xu L, Jiang WF, Qiu XB, et al: Mutational spectrum of the NKX2-5 gene in patients with lone atrial fibrillation. Int J Med Sci 11: 554-563, 2014.

12. Perera JL, Johnson NM, Judge DP and Crosson JE: Novel and highly lethal NKX2.5 missense mutation in a family with sudden death and ventricular arrhythmia. Pediatr Cardiol 35: 1206-1212, 2014.

13. Ta-Shma A, El-lahham N, Edvardson S, Stepensky P, Nir A, Perles Z, Gavri S, Golender J, Yaakobi-Simhayoff N, Shaag A, et al: Conotruncal malformations and absent thymus due to a deleterious NKX2-6 mutation. J Med Genet 51: 268-270, 2014.

14. Wang J, Zhang DF, Sun YM, Li RG, Qiu XB, Qu XK, Liu X, Fang WY and Yang YQ: NKX2-6 mutation predisposes to familial atrial fibrillation. Int J Mol Med 34: 1581-1590, 2014.

15. Zhao L, Ni SH, Liu XY, Wei D, Yuan F, Xu L, Xin-Li, Li RG, $\mathrm{Qu} \mathrm{XK}, \mathrm{Xu} \mathrm{YJ}$, et al: Prevalence and spectrum of $\mathrm{Nkx} 2.6$ mutations in patients with congenital heart disease. Eur J Med Genet 57: 579-586, 2014.

16. Wang J, Mao JH, Ding KK, Xu WJ, Liu XY, Qiu XB, Li RG, Qu XK, Xu YJ, Huang RT, et al: A novel NKX2.6 mutation associated with congenital ventricular septal defect. Pediatr Cardiol 36: 646-656, 2015.

17. Xiang R, Fan LL, Huang H, Cao BB, Li XP, Peng DQ and Xia K: A novel mutation of GATA4 (K319E) is responsible for familial atrial septal defect and pulmonary valve stenosis. Gene 534: 320-323, 2014.

18. Zhao L, Xu JH, Xu WJ, Yu H, Wang Q, Zheng HZ, Jiang WF, Jiang JF and Yang YQ: A novel GATA4 loss-of-function mutation responsible for familial dilated cardiomyopathy. Int J Mol Med 33: 654-660, 2014

19. Li J, Liu WD, Yang ZL, Yuan F, Xu L, Li RG and Yang YQ: Prevalence and spectrum of GATA4 mutations associated with sporadic dilated cardiomyopathy. Gene 548: 174-181, 2014.

20. Huang RT, Xue S, Xu YJ, Zhou M and Yang YQ: Somatic GATA5 mutations in sporadic tetralogy of Fallot. Int J Mol Med 33: 1227-1235, 2014

21. Shi LM, Tao JW, Qiu XB, Wang J, Yuan F, Xu L, Liu H, Li RG, $\mathrm{Xu}$ YJ, Wang Q, et al: GATA5 loss-of-function mutations associated with congenital bicuspid aortic valve. Int J Mol Med 33: $1219-1226,2014$ 
22. Zhang XL, Dai N, Tang K, Chen YQ, Chen W, Wang J, Zhao CM, Yuan F, Qiu XB, Qu XK, et al: GATA5 loss-of-function mutation in familial dilated cardiomyopathy. Int J Mol Med 35: 763-770, 2015.

23. Wang X, Ji W, Wang J, Zhao P, Guo Y, Xu R, Chen S and Sun K: Identification of two novel GATA6 mutations in patients with nonsyndromic conotruncal heart defects. Mol Med Rep 10 743-748, 2014

24. Xu L, Zhao L, Yuan F, Jiang WF, Liu H, Li RG, Xu YJ, Zhang M, Fang WY, Qu XK, et al: GATA6 loss-of-function mutations contribute to familial dilated cardiomyopathy. Int J Mol Med 34: 1315-1322, 2014.

25. Baban A, Postma AV, Marini M, Trocchio G, Santilli A, Pelegrini M, Sirleto P, Lerone M, Albanese SB, Barnett P, et al: Identification of TBX5 mutations in a series of 94 patients with tetralogy of Fallot. Am J Med Genet A 164A: 3100-3107, 2014

26. Zhang XL, Qiu XB, Yuan F, Wang J, Zhao CM, Li RG, Xu L, Xu YJ, Shi HY, Hou XM, et al: TBX5 loss-of-function mutation contributes to familial dilated cardiomyopathy. Biochem Biophys Res Commun 459: 166-171, 2015.

27. Zhou W, Zhao L, Jiang JQ, Jiang WF, Yang YQ and Qiu XB: A novel TBX5 loss-of-function mutation associated with sporadic dilated cardiomyopathy. Int J Mol Med 36: 282-288, 2015.

28. Pan Y, Geng R, Zhou N, Zheng GF, Zhao H, Wang J, Zhao CM, Qiu XB, Yang YQ and Liu XY: TBX20 loss-of-function mutation contributes to double outlet right ventricle. Int J Mol Med 35: 1058-1066, 2015.

29. Zhao CM, Bing-Sun, Song HM, Wang J, Xu WJ, Jiang JF, Qiu XB, Yuan F, Xu JH and Yang YQ: TBX20 loss-of-function mutation associated with familial dilated cardiomyopathy. Clin Chem Lab Med 54: 325-332, 2016.

30. Wei D, Gong XH, Qiu G, Wang J and Yang YQ: Novel PITX2c loss-of-function mutations associated with complex congenital heart disease. Int J Mol Med 33: 1201-1208, 2014.

31. Zhao CM, Peng LY, Li L, Liu XY, Wang J, Zhang XL, Yuan F, Li RG, Qiu XB and Yang YQ: PITX2 loss-of-function mutation contributes to congenital endocardial cushion defect and Axenfeld-Rieger syndrome. PLoS One 10: e0124409, 2015.

32. Wang J, Zhang DF, Sun YM and Yang YQ: A novel PITX2c loss-of-function mutation associated with familial atrial fibrillation. Eur J Med Genet 57: 25-31, 2014

33. Qiu XB, Xu YJ, Li RG, Xu L, Liu X, Fang WY, Yang YQ and Qu XK: PITX2C loss-of-function mutations responsiblefor idiopathic atrial fibrillation. Clinics (Sao Paulo) 69: 15-22, 2014.

34. Hong K and Xiong Q: Genetic basis of atrial fibrillation. Curr Opin Cardiol 29: 220-226, 2014.

35. Lyons I, Parsons LM, Hartley L, Li R, Andrews JE, Robb L and Harvey RP: Myogenic and morphogenetic defects in the heart tubes of murine embryos lacking the homeo box gene Nkx2-5. Genes Dev 9: 1654-1666, 1995.

36. Tanaka M, Chen Z, Bartunkova S, Yamasaki N and Izumo S: The cardiac homeobox gene Csx/Nkx2.5 lies genetically upstream of multiple genes essential for heart development. Development 126 : 1269-1280, 1999.
37. Jay PY, Harris BS, Maguire CT, Buerger A, Wakimoto $H$, Tanaka M, Kupershmidt S, Roden DM, Schultheiss TM, O'Brien TX, et al: Nkx2-5 mutation causes anatomic hypoplasia of the cardiac conduction system. J Clin Invest 113: 1130-1137, 2004.

38. Pashmforoush M, Lu JT, Chen H, Amand TS, Kondo R, Pradervand S, Evans SM, Clark B, Feramisco JR, Giles W, et al: Nkx2-5 pathways and congenital heart disease; loss of ventricular myocyte lineage specification leads to progressive cardiomyopathy and complete heart block. Cell 117: 373-386, 2004.

39. Lalani SR and Belmont JW: Genetic basis of congenital cardiovascular malformations. Eur J Med Genet 57: 402-413, 2014.

40. Gutierrez-Roelens I, De Roy L, Ovaert C, Sluysmans T, Devriendt K, Brunner HG and Vikkula M: A novel CSX/NKX2-5 mutation causes autosomal-dominant AV block: Are atrial fibrillation and syncopes part of the phenotype? Eur J Hum Genet 14: 1313-1316, 2006.

41. Reamon-Buettner SM and Borlak J: NKX2-5: An update on this hypermutable homeodomain protein and its role in human congenital heart disease (CHD). Hum Mutat 31: 1185-1194, 2010.

42. Baruteau AE, Probst V and Abriel H: Inherited progressive cardiac conduction disorders. Curr Opin Cardiol 30: 33-39, 2015.

43. Ellesøe SG, Johansen MM, Bjerre JV, Hjortdal VE, Brunak S and Larsen LA: Familial atrial septal defect and sudden cardiac death: Identification of a novel NKX2-5 mutation and a review of the literature. Congenit Heart Dis 11: 283-290, 2016

44. Abou Hassan OK, Fahed AC, Batrawi M, Arabi M, Refaat MM, DePalma SR, Seidman JG, Seidman CE, Bitar FF and Nemer GM: NKX2-5 mutations in an inbred consanguineous population: Genetic and phenotypic diversity. Sci Rep 5: 8848, 2015.

45. Ashraf H, Pradhan L, Chang EI, Terada R, Ryan NJ, Briggs LE, Chowdhury R, Zárate MA, Sugi Y, Nam HJ, et al: A mouse model of human congenital heart disease: High incidence of diverse cardiac anomalies and ventricular noncompaction produced by heterozygous Nkx2-5 homeodomain missense mutation. Circ Cardiovasc Genet 7: 423-433, 2014.

46. Chowdhury R, Ashraf H, Melanson M, Tanada Y, Nguyen M, Silberbach M, Wakimoto H, Benson DW, Anderson RH and Kasahara H: Mouse model of human congenital heart disease: Progressive atrioventricular block induced by a heterozygous Nkx2-5 homeodomain missense mutation. Circ Arrhythm Electrophysiol 8: 1255-1264, 2015.

47. Benson DW: Genetics of atrioventricular conductiondisease in humans. Anat Rec A Discov Mol Cell Evol Biol 280: 934-939, 2004.

48. Lu CX, Gong HR, Liu XY, Wang J, Zhao CM, Huang RT, Xue S and Yang YQ: A novel HAND2 loss-of-function mutation responsible for tetralogy of Fallot. Int J Mol Med 37: 445-451, 2016.

49. Sun YM, Wang J, Qiu XB, Yuan F, Xu YJ, Li RG, Qu XK, Huang RT, Xue S and Yang YQ: PITX2 loss-of-function mutation contributes to tetralogy of Fallot. Gene 577: 258-264, 2016. 